DOI 10.37882/2223-2982.2020.06-2.37

\title{
ОРФОГРАФИЧЕСКАЯ ВАРИАТИВНОСТЬ НЕМЕЦКИХ НАИМЕНОВАНИЙ ЗИМНИХ ВИДОВ СПОРТА (НА МАТЕРИАЛЕ КОРПУСНЫХ ДАННЫХ)
}

\section{ORTHOGRAPHIC VARIATION \\ OF GERMAN WINTER SPORTS NAMES (A CORPUS BASED CASE STUDY)}

R. Yafarov

Summary: The article analyzes the phenomenon of spelling variation among compounds in the German language which name winter sports. The study uses the data from the German Reference Corpus. The research indicates insufficient or contradictory lexicographical representation of most items and their variants. The author makes an attempt to systematize and classify selected language items, and also explores the factors which cause the orthographic variation of German winter sports names.

Keywords: German language, winter sports, text corpora, graphical variation, terminology.
$\mathrm{B}$ ариативность' относится к категории давних и актуальных проблем лингвистики. По мнению О.О. Черновой, значительный интерес к вариантности, которая обнаруживается на всех языковых уровнях, «объясняется тем, что только полное, всестороннее изучения этого феномена позволит понять принципы и законы диахронического развития и синхронного функционирования языка» [20, с. 115].

Одним из самых динамичных видов языковой вариативности является графическая (письменная) вариантность лексических единиц [4, с. 61]. В узком (традиционном) смысле под графической вариантностью понимается существование в языке орфографических эквивалентов. Письменные варианты определяются как «формальные разновидности слова, существующие лишь на письме, но не в устной речи» [11], т.е. как слова, различающиеся написанием, но не произношением, и сохраняющие семантическое тождество и тождество морфологической структуры [15, с. 64]. Отметим, что такое толкование, несмотря на свою точность и простоту, обладает одним существенным недостатком: позволяет отнести к письменным вариантам слова окказиональное или авторское визуальное изменение слова. Поэтому в
Яфаров Ринат Хамзяевич

к.филол.н., преподаватель, Московский государственный университет имени М.В. Ломоносова rinatyafarov@gmail.com

Аннотация: В данной статье подробно анализируется явление орфографической вариантности среди слов-композитов, именующих в немецком языке зимние виды спорта. Исследование проводится на основе практического материала, собранного с помощью Мангеймского корпуса немецкого языка. Автором предпринимается попытка систематизации и классификации отобранных примеров, а также дается объяснение появления тех или иных вариантов. Кроме того, показана недостаточная или противоречивая лексикографическая представленность ряда наименований и их вариантов.

Ключевые слова: немецкий язык, зимние виды спорта, корпус, графическая вариативность, терминология.

широком смысле письменная вариантность подразумевает использование метаязыковых графических знаков (косой черты, скобок, астерикса и др.) [4, с. 62] и различных альтернативных приемов кодирования текста (курсива, сплошного заглавного написания слов, полужирного шрифта и т.д.) [6]. Так, нередко можно встретить написание слов или словосочетаний полностью прописными буквами, что не является вариативностью, а объясняется приемом альтернативного графического кодирования [6]. Иллюстративная функция графических знаков [4, с. 62], реализуемая в примере ниже, позволяет печатным СМИ выделить важные рубрики и темы:

SKI FREESTYLE. Der Schweizer Skicrosser Alex Fiva hat in St. Johann im Tirol seinen ersten Weltcupsieg gefeiert (SGT, 2012).

В нашем исследовании мы ориентировались на узкое понимание графической вариативности, но не ограничивались им, поскольку в современном мире орфографическое варьирование является прямым следствием языковых контактов и одним из аспектов формальной адаптации заимствованных слов [9, с. 158-163]. Среди прочих причин появления орфографических вариантов лингвисты называют:

В данной работе мы используем термины «вариантность» и «вариативность» в качестве синонимов. Несмотря на предпринимаемые попытки разграничения данных понятий [14, с. 32-33; 16, с. 70-79; 20], решающей во многих исследованиях остается авторская позиция. 
1. либерализацию и демократизацию языка, отсутствие четкой нормы и актуальной лексикографической фиксации слов, в том числе заимствованных [18];

2. языковую эволюцию, несовершенство действующих правил правописания, различную лингвистическую интерпретацию языковых явлений, плюрализм языковых средств для передачи того или иного содержания, графическую адаптацию неологизмов и, как следствие, двойную орфографическую мотивацию [10; 13];

3. языковое творчество и возросшую роль интернет-коммуникации [12]; 5) неодобрение и неприятие обществом новых правил орфографии [19].

Причины орфографического варьирования в сложных существительных немецкого языка исследователи видят в ремотивировке слова; в стремлении облегчить восприятие слова или избавить читателя от ложной мотивировки; в использовании нового написания в рекламных целях или выделении в лексеме важной смысловой конституенты; В заимствовании иностранного написания [22, с. 37-45; 24, с. 193-194], а также в региональных отличиях [25, с. 245].

Не стоит также забывать о таком факторе, как неграмотность авторов письменных текстов или игнорирование существующих норм правописания.

С вариантностью связаны такие важные понятия, как инвариант и норма. Если для существования вариантов наличие инварианта не всегда обязательно [17], то норма - это своего рода узаконенный вариант [14, с. 19-22]. Один из способов нормализации заключается в лексикографической фиксации, которая обладает двумя существенными недостатками: отставанием от актуального состояния языка и субъективизмом и избирательностью составителей [14, с. 24- 27].

Вариантность обнаруживается также в терминологии - наиболее регламентированном пласте лексики. Это объясняется как открытостью большинства специальных языков, так и наличием у термина языкового субстрата [8]. Распространено мнение, что варианты мешают профессиональному общению, могут внести хаос и недопонимание в коммуникацию между специалистами одной и той же области знания или сферы деятельности и даже застопорить развитие специальной области. Тем не менее, факт существования терминологической вариантности учеными признается [1, с. 38-49; 3, с. 105-108; 7, c. 140-141].

Настоящее исследование посвящено графическим вариантам сложных (компо́зитных) наименований зимних видов спорта в немецком языке. Выбор данного объекта изучения был обусловлен двумя факторами. Во-первых, немецкий язык отличает склонность к образованию сложных существительных [25, с. 245], компонентами которых нередко могут быть более двух корней. О широко распространенной вариантности в данном пласте лексики свидетельствуют достаточно подробные, но не всегда однозначные орфографические правила, приводимые в авторитетных лингвистических изданиях [22; 24].

Вторая причина заключается в возросшей значимости зимнего спорта в мире и, как следствие, активном слово- и терминообразовании в данном подъязыке. Так, на сайте «Wikipedia» в статье «Зимние виды спорта» [5] перечислены почти шестьдесят видов. По нашим подсчетам, только во второй половине XX - начале XXI вв. появилось более 30-ти новых видов спортивной деятельности на льду и снегу. Несмотря на неоднозначность толкования самого термина «спорт» [ср. 2, с. 358 и 26, с. 405], очевиден факт пополнения немецкого языка названиями видов спорта, большинство которых - сложные и/ или заимствованные лексические единицы.

Исследование проводилось на материале корпуса немецкого языка Мангеймского университета [21]. К общепризнанным достоинствам лингвистических корпусов относят:

а) их соответствие современной парадигме перехода от «системы» К «узусу» и от «языка» к «речи» $[13$, с. 8];

б) фиксация ими картины «живого» языка; в) их объем и репрезентативность.

В ходе исследования были выполнены следующие задачи:

а) отбор и анализ композитов-названий видов спорта и их орфографических вариантов;

б) сравнение корпусных данных с данными словарей «Duden Online-Wörterbuch» [23] и «Duden Die deutsche Rechtschreibung» [22] как наиболее полных и авторитетных источников, содержащих информацию о словарном составе немецкого языка и принятом правописании;

в) объяснение причин и факторов возникновения вариативности в отобранном материале.

Объектом анализа выступили не просто лексемы, но корпусные тексты, т.е. тексты дискурса, в которых специальные слова функционируют и проявляют свои вариантные свойства. Однако необходимо оговориться, что, несмотря на множество преимуществ, корпуса имеют ряд недостатков, которые следует учитывать в работе с ними. Во-первых, каким бы большим ни был корпус национального языка, он все равно не полон, т.к. не содержит всех текстов на том или ином языке. Объем конкретного корпуса, как правило, ограничен целями, подходами и техническими возможностями его составителей, а пополнение текстовой базы занимает значительное количество времени. Во-вторых, большинство 
корпусов - это банки данных исключительно письменных текстов. В-третьих, тексты могут быть внесены с погрешностями, т.е. неверно распознаны, а слова в них неверно размечены. Так, в примере ниже перенос лексемы Freestyle в оригинальном тексте по какой-то причине был оцифрован с пробелом, из-за чего поисковая система корпуса [21] расценивает Free-style как два отдельных слова: Die gewonnene Bewegungsfreiheit führte zu neuen Disziplinen, wie dem Free- style, dem Skysurfen und dem Headdownspringen (LR, 04.05.2001).

Для исследования были отобраны 186 наименований для 70 традиционных и новых видов зимнего спорта. Количество обнаруженных вариантов составило 517 единиц. Другими словами, в среднем на один вид спорта приходится три синонимичных наименования-композита, а на одну лексему - до трех вариантов написания. Общее количество найденных и рассмотренных словоупотреблений данных вариантов (включая их словоформы) - 1.018.918. Двух- и трёхкомпонентные названия составили приблизительно по 47\% от общей выборки, четырёхкомпонентные - около 6\%.

На основе обнаруженной вариативности мы составили классификацию, согласно которой можно условно выделить:

а) комбинационные варианты;

б) графемные (буквенные) варианты;

в) варианты на основе гибридных слов;

г) смешанные варианты.

Далее остановимся на каждой группе подробнее.

Под комбинационными вариантами мы подразумеваем типы графического соединения компонентов сложного слова в одну лексему. Анализ показал, что наиболее редким типом варьирования в данной категории является перестановка конституентов в названии: NordicWinter-Walking / Winter-Nordic-Walking. На втором месте по распространенности оказалось раздельное/слитное написание лексем: Speed Riding/Speedriding, Snow Surfing / Snowsurfing и др. Такое варьирование характерно для заимствованных английских слов. Самым частотным стало варьирование типа «слитное/дефисное написание»: Freestyle-Skiing / Freestyleskiing, Minibobrennen / MinibobRennen и др. Заимствованные лексемы могут иметь все три способа написания (напр., Speed Skiing / Speedskiing / Speed-Skiing). В случае, когда композит имеет три корня и более, дефис может стоять между любой частью слова или отделять каждый корень: Eis-Speedway-Rennen / Eis-Speedwayrennen / Eisspeedway-Rennen. Тем не менее, в подобных рядах, как правило, преобладает написание, благодаря которому дефис делит слово на две наиболее значимые части (Minibob-Rennen, Speedski-Sport) и/или на компоненты, один из которых выполняет словообразовательную функцию (Karting (картинг) $\rightarrow$ Eis-Karting (кар- тинг на льду), Skibob (скибоб) $\rightarrow$ Skibob-Rennen (скибоббинг) и т.п.).

Перечислим несколько причин данного варьирования:

1. заимствование англоязычного слова и частично его оригинального написания;

2. отсутсвие слова в лексикографических источниках и, как следствие, правильного варианта, на который следует ориентироваться;

3. стремление к удобству восприятия и так называемой обозримости слова (ср.: Woksport / WokSport, Skiorientierungslauf / Ski-Orientierungslauf, Geschwindigkeitsskifahren / Geschwindigkeits-Skifahren).

Абсолютное преобладание слитно написанных сложных слов наблюдается у наименований, давно существующих в языке. Как правило, такие слова называют виды спорта, имеющие долгую историю, а сами слова нередко зафиксированы в словарях. Доля вариантов слитного написания в каждом случае колеблется в пределах 50-97\%. Среди наименований новых или относительно молодых видов зимнего спорта дефисное написание в редких случаях может преобладать (например, Ice-Karting встречается чаще, чем Ice Karting, Wok-Rennen - чаще, чем Wokrennen) или количественно быть равным (SnowVolleyball / Snowvolleyball, Para-Ski / Paraski).

Появление графемных вариантов обусловлено различиями в передаче на письме одинаковых фонем. В основе такой вариантности могут лежать:

а) сосуществование двух норм или допустимых способов написания (Schibob / Skibob, Schikjöring / Schijöring, Eisstockschiessen / Eisstockschießen);

б) орфографические ошибки (Schlittenhunderennen / Schlittenhunderrennen, Schneeschuh-Trekking / Schneeschuh-Ttrecking / Schneeschuh-Tracking, Ski alpin (нормативный вариант) / Ski Alpin / Ski Alpine / Skialpin / Ski-alpin / Ski-Alpin, Schneetubing / Schneetubbing);

в) процесс фонетико-графической ассимилции заимствованных лексем (snow kayaking $\rightarrow$ Snowkayaking/Snowkajaking).

В первом случае один из вариантов является в синхронном срезе, как правило, частотным (напр., Ski), а сточки зрения синхронии, вытесняет другой вариант (Schi). Варианты из-за орфографических ошибок в процентном соотношении крайне малочисленны и, по всей видимости, возникают в письменных текстах постоянно. Наконец, мы полагаем, что орфографическое варьирование в процессе ассимиляции может быть изменено в сторону преобладания конкретного написания в первую очередь благодаря нормированию и лексикографической фиксации заимствованной лексики. 
Необычным примером графемной вариантности представляется название катания на санках мини-боб: Zipfelbob-Rennen / Zipflbob-Rennen и Zipfybob-Rennen / Zipfibob-Rennen. Пара Zipfelbob / Zipflbob возникла под действием фонетико-графических и региональных факторов. Слово Zipfy одновременно является наименованием канадской марки санок и названием самих санок. Компонент Zipfi-, по всей видимости, стоит рассматривать как фонетико-графическое искажение лексемы Zipfy.

В особую группу мы выделили гибридные (билингвальные) композиты, т.е. слова, состоящие из этимологически разных корней и варьирующихся по данному признаку. Так, лексемы Icekarting / Eiskarting, Icespeedway / Eisspeedway и т.п. произносятся практически одинаково, имеют идентичное значение, но отличаются написанием одного компонента. Набор таких признаков формально совпадает с определением графических вариантов, приведенным в начале статьи. В эту же группу мы относим пары «заимствованное слово/эквивалент-калька»: Snow Rugby / Schnee-Rugby, Snowsurfen / Schneesurfen и т.п. Строго говоря, данное явление представляет собой пример структурного варьирования и морфологической ассимиляции. Тем не менее, слова ice и Eis, snow и Schnee в рамках языка и дискурса зимнего спорта являются абсолютными синонимами, возникшими в результате графической адаптации англоязычных названий видов спорта. Полагаем, что до тех пор, пока один из вариантов не будет окончательно кодифицирован, а значит, закреплен в языке и возведен в статус нормы, подобные пары композитов можно считать графическими вариантами.

Стоит, однако, отметить, что даже в случае абсолютной морфологической и семантической эквивалентности со временем выбор делается в пользу автохтонного слова, т.е. слова с более ясной мотивировкой. Наглядным примером служит пара Snow-Zorbing / Schnee-Zorbing (сноузорбинг), не зафиксированная в словаре «Duden». В корпусе было обнаружено всего по два случая употребления данных вариантов. Написание Snow-Zorbing является самым ранним и встречается в текстах 2005 и 2006 гг. Именно в тот период зародился этот вид спорта. Однако в более поздних текстах (2010 и 2015 гг.) используется только ассимилированный вариант: Schnee-Zorbing. Так, в словаре «Duden» закреплены слова-синонимы: менее ассимилированное Snowkiting и «онемеченное» Snowkiten. С другой стороны, интернациональное наименование Snow-Zorbing будет по-прежнему употребляться в устной и письменной речи, а институализация и мировое распространение сноузорбинга, вероятно, склонят чашу весов в сторону англоязычного варианта. K примеру, немецкие кальки Schneebrettfahren и Off-PisteSkifahren не смогли вытеснить соответствующие интернациональные и общеизвестные лексемы Snowboarding и Freeriding.
Смешанные варианты сочетают в себе как различное соединение компонентов слова, так и амбивалентность в написании отдельных букв: Schijöring / Schi-Jöring / Schikjöring / Skijöring / Ski-Jöring / Skikjöring / Ski-Kjöring, Schlittenhundenrennen / Schlittenhunden-Rennen / Schlittenhunderennen / Schlittenhunde-Rennen / Schlitten-Hunderennen / Schlitten-Hunde-Rennen. Однако, как правило, в дискурсе преобладают один-два варианта.

Особенностью названий видов спорта является принадлежность данных лексем как к спортивному, так и к общему языку. Варианты возникают не только в речи спортсменов и спортивных журналистов, но и благодаря их употреблению широким кругом людей. Распространение орфографического варьирования в языке зимнего спорта свидетельствует об открытости спортивного дискурса, различном уровне грамотности и фоновых знаний авторов текстов, общих тенденциях в языке и обществе (в частности, влиянии американского английского).

Другим фактором появления и закрепления определенного варианта является, по-видимому, возраст спорта и степень его институционализации. Так, вариантные написания олимпийских видов спорта с долгой историей (например, Eis-Hockey вместо Eishockey, Snow-Boarden вместо Snowboarden, Eis-Lauf вместо Eis-Lauf) встречаются крайне редко и в процентном соотношении не могут конкурировать с закрепленной нормой.

Среди рассмотренных названий видов спорта лишь 37 единиц представлены в словарях «Duden» [22; 23], для 12 из них указаны орфографические варианты (например, Schilaufen / Skilaufen, Heliskiing / Heli-Skiing, Snowrafting / Snow-Rafting и др.). Несмотря на заявляемую редакцией политику активного поиска и отбора новых слов на основе корпусов немецкого языка [27], очевидно, что терминология зимнего спорта в словаре представлена недостаточно. В наиболее авторитетном лексикографическом источнике немецкого языка можно найти названия лишь около десятка зимних видов спорта. Кроме того, в словаре отсутствуют высокочастотные синонимы зафиксированных лексем, например: Eislaufen для Eislauf, Eisfischen для Eisangeln, Schneeschuhlaufen для Schneeschuhwandern и др.

В большинстве случаев была установлена прямая корреляция между частотностью формы и включенностью ее в словник. Однако неясным и противоречивым остается выбор некоторых орфографических вариантов, в том числе тех, которым, согласно пометам словаря, следует отдать предпочтение. Так, в парах Freeriding / Free Riding и Freeskiing / Free Skiing варианты с раздельным написанием встречаются в корпусе в десятки раз реже. Не включенный в словарь вариант EisspeedwayRennen в полтора раза частотнее, чем зафиксирован- 
ный Eisspeedwayrennen. Для лексем Paraski, Shorttrack, Skilanglauf в словнике отсутствуют их распространенные варианты: Para-Ski, Short-Track / Short Track и Ski-Langlauf соответственно. Перечисленные недостатки и противоречия словаря «Duden» говорят как об отставании лексикографической работы от языковой действительности, так и о сложном выборе между дескриптивным и прескриптивным подходом, который делают редакторы во время фиксации тех или иных орфографических вариантов.

Таким образом, на основе полученных данных можно сделать следующие выводы:

1. корпус национального языка предоставляет значимую информацию о графической вариантности слов и выступает индикатором языковых трендов;

2. на примере графических вариантов мы наблюдаем вечную борьбу нормы и узуса, традиционного и окказионального написания, автохтонного и модного заимствованного слов;

3. композиты немецкого языка обладают высокой степенью орфографической вариативности, которая не всегда связана с количеством конституентов;

4. в немецкоязычных словарях представлена лишь небольшая часть названий зимних видов спорта и их орфографических вариантов; лексикографическая фиксация специальных лексем и/или их частотных формальных вариантов способствует их нормированию, а кодификация заимствованных лексем - их ассимиляции;

5. причины вариативности названий видов спорта в немецком языке могут быть как лингвистическими, так и экстралингвистическими; однако в дальнейшем и более углубленном изучении нуждаются когнитивные факторы возникновения графических вариантов.

\section{ЛИТЕРАТУРА}

1. Авербух К.Я. Терминологическая вариантность: теоретический и прикладной аспекты // Вопросы языкознания. - 1986. - № 6. - С. 38-49.

2. Блеер А.Н. и др. Терминология спорта. Толковый словарь-справочник. - М.: Академия, 2010. - 464 с.

3. Гринев-Гриневич С.В. Терминоведение: учеб. пособие для студ. высш. учеб. заведений. - М.: Академия, 2008. - 304 с.

4. Едличко А.И. Графическая вариативность как феномен политкорректности // Вестн. Моск. ун-та. Серия 19: Лингвистика и межкультурная коммуникация. - 2018. - № 4. - С. 60-68.

5. Зимние виды спорта //Wikipedia. - URL: https://ru.wikipedia.org/wiki/Зимние_виды_спорта (дата обращения: 10.04.2020).

6. Климик В.А. Приёмы альтернативного графического кодирования в англоязычном художественном тексте: свойства и функции // Вестн. Моск. гос. обл. ун-та. Серия: Лингвистика. - 2017. - № 1. - С. 99-107. - D0I: 10.18384/2310-712Х-2017-1-99-107.

7. Лейчик В.М. Лексическая вариантность и ее развитие в системе, норме и речи // Вариантность как свойство языковой системы: тезисы докладов. - Ч. 2. - М.: Наука, 1982. - С. 140-141.

8. Лейчик В.М. 0 языковом субстрате термина // Вопросы языкознания. - 1986. - № 5. - С. 87-97.

9. Маринова Е.В. Иноязычная лексика современного русского языка : учеб. пособие. - М.: ФЛИНТА: наука, 2012. - 288 с.

10. Нечаева И.В. 0 явлении и случаях двойной орфографической мотивации // Вопросы культуры речи. Вып. ХІ. М., Языки славянской культуры, 2012. - С. $148-152$.

11. Нечаева И.В. Что такое орфографические варианты и почему они появляются в языке. - URL: http://gramma.ru/RUS/?id=1.83 (дата обращения: 10.04.2020).

12. Осетрова 0.И. Заимствования интернет-коммуникации: проблема орфографической вариативности и ее отражение в словарях // Филологические науки. Вопросы теории и практики. - 2018. - № 3-1 (81). - С. 160-163.

13. Плунгян В.А. Корпус как инструмент и как идеология: о некоторых уроках современной корпусной лингвистики // Русский язык в научном освещении. М., 2008. - № 2 (16). - C. 7-20.

14. Попов С.Л. Русская грамматическая вариантность в когнитивно-эволюционном освещении: Монография. - Харьков: «Міськдрук», 2014. - 304 с.

15. Руссу А.Н. Вариантность слова в немецком обиходно-разговорном языке // Вестн. Челяб. гос. ун-та. - 2014. - № 23 (352). - С. 64-69.

16. Сложеникина Ю.В. Терминологическая вариативность: Семантика, форма, функция. Изд. 2-е, испр. - М.: Изд-во ЛКИ, 2010. - 288 с.

17. Солнцев В.М. Вариативность как общее свойство языковой системы // Вопросы языкознания. - 1984. - № 2. - С. 31-42.

18. Тумакова Е.В., Азанов Л.Э. Орфографическая вариативность в современных письменных текстах // Академическая наука - проблемы и достижения: материалы международной научно-практической конференции, North Charleston, USA, 24-25.10.2016. - North Charleston: CreateSpace, 2016. - C. 144-146.

19. Фадеева А.В. Предпосылки орфографических реформ немецкого письменного языка // Вестн. Моск. гос. обл. ун-та. Серия: Лингвистика. - 2009. № 3. - C. 202-205.

20. Чернова 0.0. К вопросу о языковой вариативности // Современные подходы к изучению единиц языка и речи и вопросы лингводидактики: сб. науч. трудов. - Белгород: ИПЦ «Политерра», 2012. - С. 115-118.

21. DeReKo - Das Deutsche Referenzkorpus des IDS Mannheim im Portal COSMAS II. - URL: https://cosmas2.ids-mannheim.de/cosmas2-web (дата обращения: 10.04.2020).

22. Duden - die deutsche Rechtschreibung. 27., völlig neu bearbeitete und erweiterte Auflage. - Berlin: Dudenverlag, 2017. - 1264 S. 
23. Duden-Onlinewörterbuch. - URL: http://www.duden.de (дата обращения: 10.04.2020).

24. Fleischer W., Barz I. Wortbildung der deutschen Gegenwartssprache. - Berlin: de Gruyter, 2012. - 484 S.

25. Klein W.P. Sprachliche Zweifelsfälle im Deutschen: Theorie, Praxis, Geschichte. - Berlin/Boston: de Gruyter, 2018. - 367 S.

26. Schülerduden. Der Sport. Ein Sachlexikon für die Schule / H. Haag (Hrsg.), G. Kwiatkowski (Hrsg.). - Mannheim; Wien; Zürich: Bibliographisches Institut, 1987. - 492 S.

27. Wie kommt ein Wort in den Duden? - URL: https://www.duden.de/ueber_duden/wie-kommt-ein-wort-in-den-duden (дата 0бращения: 10.04.2020).

(с) Яфаров Ринат Хамзяевич (rinatyafarov@gmail.com).

Журнал «Современная наука: актуальные проблемы теории и практики»

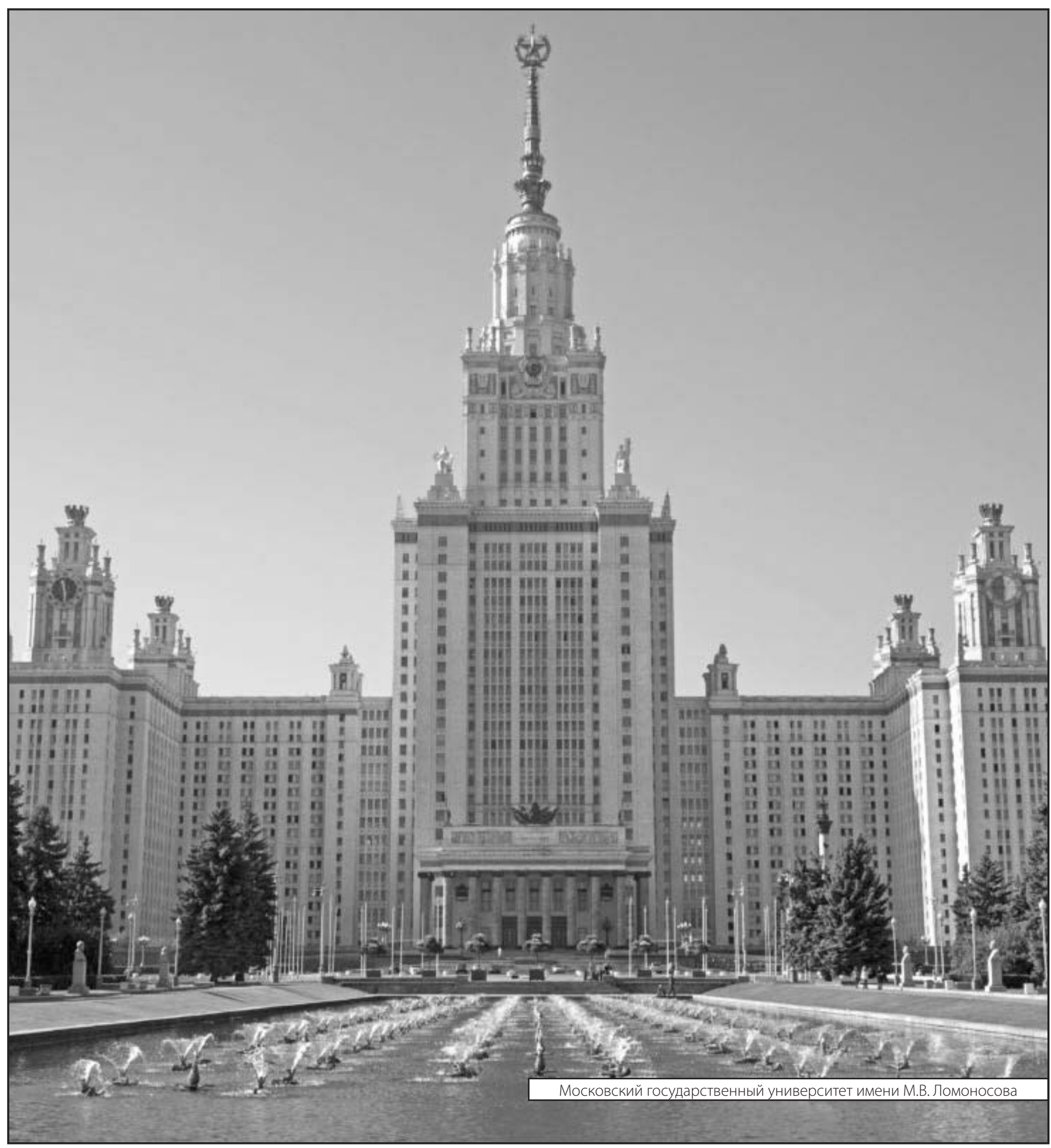

